\title{
National Scale Monitoring, Reporting and Verification of Deforestation and Forest Degradation in Guyana
}

\author{
P. Bholanath ${ }^{\mathrm{a}}$, K. Cort ${ }^{\mathrm{b}}$ \\ ${ }^{a}$ Guyana Forestry Commission, Planning and Developmnet Division, 1 Water Street, Kingston, Georgetown, Guyana - \\ project.coordinator@forestry.gov.gy \\ ${ }^{\mathrm{b}}$ Guyana Forestry Commission, Manager, Forest Area Assessment Unit, 1 Water Street, Kingston, Georgetown, Guyana - \\ kerryanne.cort@gmail.com
}

KEY WORDS: Deforestation, Forest Degradation, Landsat, RapidEye, MRV System, and persistent cloud.

\begin{abstract}
:
Monitoring deforestation and forest degradation at national scale has been identified as a national priority under Guyana's REDD ${ }^{+}$ Programme. Based on Guyana's MRV (Monitoring Reporting and Verification) System Roadmap developed in 2009, Guyana sought to establish a comprehensive, national system to monitor, report and verify forest carbon emissions resulting from deforestation and forest degradation in Guyana. To date, four national annual assessments have been conducted: 2010, 2011, 2012 and 2013 .
\end{abstract}

\begin{abstract}
Monitoring of forest change in 2010 was completed with medium resolution imagery, mainly Landsat 5. In 2011, assessment was conducted using a combination of Landsat (5 and 7) and for the first time, $5 \mathrm{~m}$ high resolution imagery, with RapidEye coverage for approximately half of Guyana where majority of land use changes were taking place. Forest change in 2013 was determined using high resolution imagery for the whole of Guyana. The current method is an automated-assisted process of careful systematic manual interpretation of satellite imagery to identify deforestation based on different drivers of change. The minimum mapping unit (MMU) for deforestation is 1 ha (Guyana's forest definition) and a country-specific definition of 0.25 ha for degradation.
\end{abstract}

The total forested area of Guyana is estimated as 18.39 million hectares (ha). In 2012 as planned, Guyana's forest area was reevaluated using RapidEye $5 \mathrm{~m}$ imagery. Deforestation in 2013 is estimated at 12733 ha which equates to a total deforestation rate of $0.068 \%$. Significant progress was made in 2012 and 2013, in mapping forest degradation. The area of forest degradation as measured by interpretation of 5 m RapidEye satellite imagery in 2013 was 4352 ha. All results are subject to accuracy assessment and independent third party verification.

\section{Introduction}

Historical deforestation in Guyana has been very low $(0.02 \%$ to $0.079 \% \mathrm{yr}^{-1}$ over the past 22 years), but this trend may change in the future as deforestation increases to meet growing demands for agriculture, timber, minerals, and human settlements. Guyana is therefore considered to be a high forest cover low emission/deforestation rate (HFLE/D) country, with forests covering approximately $85 \%$ of the country (forest area of 18.5 million hectares) and containing an estimated 19.5 billion tons (or $\mathrm{Gt}$ ) of $\mathrm{CO}_{2}$ in live and dead biomass pools.

In addition to being one of Guyana's most valuable natural assets, these forests are suitable for logging and agriculture, and are underlain with significant mineral deposits. Mining has been the primary driver of deforestation in Guyana, accounting for approximately $60 \%$ of all deforestation between 1990 and 2009 and more than $90 \%$ of deforestation between 2009 and 2012 . Other drivers include forestry infrastructure, agriculture, and other infrastructure.

The Joint Concept Note (JCN) between the Government of Guyana and the Government of the Kingdom of Norway identifies the stepwise and progressive development of the Guyana Monitoring Reporting and Verification System (MRVS) based on REDD+ Interim Indicators and reporting requirements. The intention is that these interim measures will be phased out as the full-fledged MRVS is established. Guyana's MRVS, which is composed of the Forest Area
Assessment System and the Forest Carbon Monitoring System (FCMS) form the link between historical assessments and current/future assessments, enabling consistency in the data and information to support the implementation of REDD+ activities.

The initial steps of the MRVS allowed for a historical assessment of forest cover to be completed, key database integration to be fulfilled and for interim/intermediate indicators of emissions from deforestation and forest degradation to be reported for subsequent periods. The basis for comparison of the area-based interim measures is the 2009 September Benchmark Map. Four annual Forest Area Assessments have been completed so far. The first reporting period (termed Year 1) is set from 01 October 2009 to 30 September 2010 with the second reporting period (Year 2) covering 01 October 2010 to 31 December 2011, a fifteen (15) month period. The Year 3 and Year 4 reports both cover the 2013 and 2014 calendar years, respectively.

The transition from medium resolution $(30 \mathrm{~m})$ Landsat to high resolution RapidEye images ( $5 \mathrm{~m}$ pixel resolution) has increased the opportunity to better delineate and detect land use change. The analysis is subject to independent audit, firstly by the accuracy assessors University of Durham (UoD) and secondly by the project verifiers Det Norske Veritas (DNV).

An accompanying and closely connected programme of work is being implemented by Guyana Forestry Commission (GFC), with the assistance of a specialist firm (Winrock International) is the development of a national forest carbon measurement 
system and related emission factors. This programme will establish national carbon conversion values, expansion factors, wood density and root/shoot ratios as necessary. The MRVS details the methods required to quantify the changes in forest cover and changes in forest carbon stocks in Guyana, develop driver-specific emission factors by forest strata, and monitor emissions from land cover/land use change over time based on a variety of management activities.

This paper provides a summarised description of the work undertaken to complete the annual forest area assessments.

\subsection{Country Description}

The total land area for Guyana is 21.1 million hectares (ha) and spans from 2 to $8^{\circ} \mathrm{N}$ and 57 to $61^{\circ} \mathrm{W}$. Guyana shares common borders with three countries: to the north-west - Venezuela, the south-west - Brazil, and on the east - Suriname. Guyana's 460 $\mathrm{km}$ coastline faces the Atlantic on the northern part of the South American continent. The coastal plain is only about $16 \mathrm{~km}$ wide but is $459 \mathrm{~km}$ long.

It is dissected by 16 major rivers and numerous creeks and canals for irrigation and drainage. The main rivers that drain into the Atlantic Ocean include the Essequibo, Demerara, Berbice, and Corentyne. These rivers have wide mouths, mangroves, and longitudinal sand banks so much associated with Amazonia, and mud flows are visible in the ocean from the air. The geology in the centre of the country is a white sand (zanderij) plateau lying over a crystalline plateau penetrated by intrusions of igneous rocks which cause the river rapids and falls.

\subsection{Land Eligible under Guyana's LCDS}

The Low Carbon Development Strategy (LCDS) outlines a national programme that aims to protect and maintain its forests in an effort to reduce global carbon emissions and at the same time attract resources to foster growth and development along a low carbon emissions path. Under the Memorandum of Understanding (MOU) between Guyana and Norway, not all land is included in Guyana's LCDS, only lands under the ownership of the State. Tenure classifications in Guyana were changed in 2013 to include protected areas along with State Land, State Forest and Amerindian Land. This change meant that Iwokrama Forest Reserve and Kaieteur National Park are now amalgamated into the new single class termed 'Protected Areas' for technical classification although still separate for administrative purposes.

\subsection{Establishing Forested Area}

Land classified as forest follows the definition as outlined in the Marrakech Accords (UNFCCC, 2001). Guyana has elected to classify land as forest if it meets the following criteria:

Tree cover of minimum $30 \%$

At a minimum height of $5 \mathrm{~m}$

Over a minimum area of 1 ha.

In summary, the process used to define the national forest cover involved:

Determination of the 1990 forest area using medium resolution satellite images (Landsat) by excluding non-forest areas (including existing infrastructure) as at 1990.
From this point forward accounting for forest to non-forest land use changes that have occurred between 1990 and 2010 using a temporal series of satellite data.

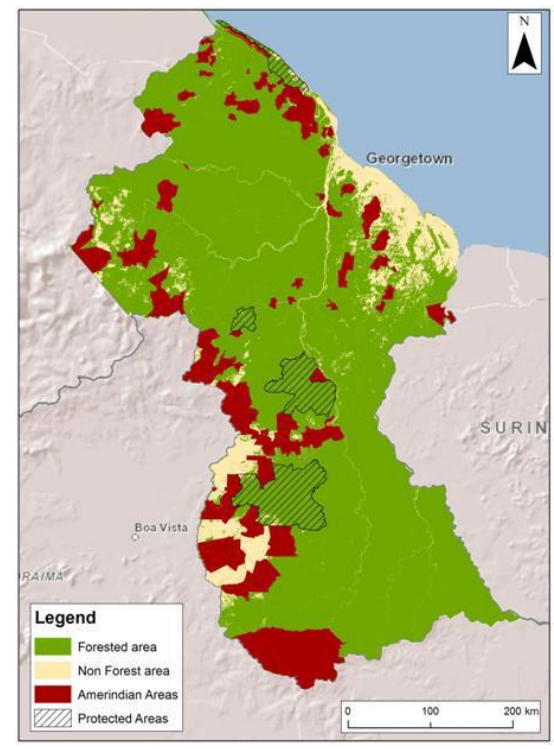

Figure 1: Land classes of Guyana

The 2010 Interim Measures report estimated that as at the benchmark period (30 September 2009) the total forest area that met the above definition was 18.39 million ha $( \pm 0.41$ million ha). This figure was further verified by the University of Durham (UoD) with an indicative accuracy of (97.1\%).

The 2012 (Year 3) assessment used a forest area (including State Land, State Forest and Amerindian Villages) of 18.50 million ha as the starting point. The increase in forest area resulted from the re-analysis of the 1990 forest / non-forest classification. These boundaries were updated using $5 \mathrm{~m}$ satellite imagery. This was a necessary change in order to ensure the delineation of mapped change events are at a consistent resolution with the updated forest / non-forest boundary. This means that historical change was included in the reported forest area figures until year two. From year three forward, the analysis does not take into account historical change mapped from Landsat. This entails comparing different analyses based on imagery of significantly different resolution. To generate a truly comparative figure, a full 'back cast' analysis of historical change events at the updated RapidEye resolution would be necessary. This is a comprehensive exercise and would essentially entail an extensive long term analysis of all historical mapping periods, with reference to all historical imagery.

\section{Monitoring \& Spatial Datasets}

The datasets used for the change analysis have evolved over time. This progression is outlined as follows:

1990 to 2000 - Landsat $30 \mathrm{~m}$

2001 to 2005 - Landsat $30 \mathrm{~m}$

2006 to 2009 September - Landsat $30 \mathrm{~m}$

2009 - 2010 October (Year 1) - Landsat $30 \mathrm{~m}$ and DMC $22 \& 32 \mathrm{~m}$

2010- 2011 December (Year 2) Landsat $30 \mathrm{~m}$ and RapidEye $5 \mathrm{~m}$

2012 December (Year 3) RapidEye 5 m supplemented as necessary by Landsat $5 \& 7$ 
2013 December (Year 4) RapidEye 5 m supplemented as necessary by Landsat 8

It is worth noting that currently there are very few operational medium resolution satellite systems that are freely available, or that obtain images frequently enough to allow national reporting of change. To reduce the risk of inadequate coverage GFC has invested in the tasking of an individual satellite data provider. The overall aim is to improve operational methods and to phase out or replace the interim measures.

\subsection{RapidEye}

The RapidEye constellation consists of five satellites which have been providing high resolution multi-spectral images since the start of RapidEye's commercial operations in February 2009. RapidEye holds imagery in an online image archive, and is also available to be tasked to cover specific areas. RapidEye provides both ' $1 \mathrm{~B}$ ' and ' $3 \mathrm{~A}$ ' 5 m resolution products.

The decision to commission this coverage was to ensure national coverage at a resolution high enough to capture forest change and degradation activities. The coverage also allows for robust estimates of change - as required for the national MRVS. GFC has tasked the RapidEye constellation to provide a countrywide coverage of Guyana.

Since 2012 GFC has progressively improved the positional accuracy of the RapidEye image base. This process initially involved co-registering the RapidEye 'image swaths' to match the existing Geo-Cover base map. The updated tie points were then returned to RapidEye and used to correct 2013 (Year 4) image coverage.

In 2014 RapidEye updated the positional accuracy over Guyana using control points derived from VHR (Very High Resolution) Digital Globe imagery. In the West of Guyana an offset of up to $30 \mathrm{~m}$ is observed. This is due to the steep topographic relief and change in the UTM zone to $20 \mathrm{~N}$.

It is proposed for Year 5 that the GFC team update and improve the existing base maps using RapidEye's improved 3A orthocorrected product. The revised basemap will be used as a reference from the next reporting period onwards.

For the analysis a higher priority is placed on images acquired at the end Year 4 reporting period, with the majority of images acquired in November 2013. Due to the typically cloudy nature of satellite imagery over Guyana multiple scenes over the same location are required. Nearly all areas have three separate images covering each footprint. Supplementary to the RapidEye acquisition, $30 \mathrm{~m}$ Landsat 8 data is also analysed. Wall to wall coverage of Landsat imagery for Guyana has been downloaded from the United States Geological Survey (USGS) online catalogue.

\subsection{Landsat}

Landsat 8 imagery launched on 11 February 2013 also provides temporal coverage over Guyana. This imagery is archived and is freely available and can be sourced from either the United States Geological Survey (USGS) or National Institute for Space Research (INPE) Brazil. Imagery sourced through USGS comes processed as "L1T" or terrain corrected (using SRTM 90 m DTM), whereas INPE imagery typically does not.
Landsat acquires images over the same area every 16 days. The Landsat Data Continuity Mission Landsat 8 provides a source of freely available imagery at $30 \mathrm{~m}$ resolution. The sensor collects 11 spectral bands from visible $(\sim 0.5 \mu \mathrm{m})$ to thermal $(\sim 12 \mu \mathrm{m})$ wavelengths.

\subsection{Accuracy Assessment Datasets}

The purpose of the Accuracy Assessment (AA) is to provide an assessment of the quality of the GFC's mapping of land cover land use change across Guyana. It is established practice that data used for accuracy assessment be either an independent interpretation of the same datasets used for the change mapping or, if available, higher resolution data.

Currently, there are no commercially available satellites capable of supplying imagery of sufficiently high spatial resolution with appropriate revisit frequency on a national scale. The accuracy assessment conducted for Year $2(2011-12)$ noted that a pixel size of at least $1-2 \mathrm{~m}$ is needed to identify forest degradation resulting from human infrastructure.

As part of a continuous improvement process GFC and Indufor Asia Pacific have developed an operational method that captures high-resolution aerial imagery using a highly portable aerial multispectral imaging system. The camera system (provided by GeoVantage) is a flexible unit that can be installed quickly and easily on to various models of light aircraft. The resolution of the images captured across Guyana ranged from about 25 to $60 \mathrm{~cm}$, a resolution capable of identifying forest degradation with some certainty.

The strategy employed uses the imaging system to capture highquality image data at sites pre-determined by a stratified random sample that covers the majority of Guyana. The full sample coverage is achieved by including the RapidEye images over areas where it is not possible to safely operate a small aircraft.

The locations of these transects were provided to Indufor by the independent accuracy assessment team from Durham University, UK. Individual image frames acquired over the sample site locations were stitched together to form a mosaic. The mosaics obtained from the system were then delivered to the accuracy assessment team for analysis. The system is versatile enough to operate at low altitude $(2000 \mathrm{ft})$ which increases flexibility in cloudy conditions.

In Year 3 the Accuracy Assessment involved the collection of 143 sample units randomly selected from primary sampling units. The accuracy assessment in Year 3 was carried out primarily using GeoVantage aerial imagery. Therefore in order to generate the best possible change reference dataset a repeat coverage of aerial imagery was acquired for Year 4.

It is recognised that there are practical and operational difficulties in generating an identical dataset with perfect overlap between Years 3 and 4. For example, there will be areas where GeoVantage data are missing or cannot be collected in areas where long-range flights with a light aircraft are not feasible or safe. In such cases the best available RapidEye data were selected and reinterpreted. Where possible the RapidEye data were used in parts of the low risk stratum where human access is particularly limited and there is no history of logging or mining. 


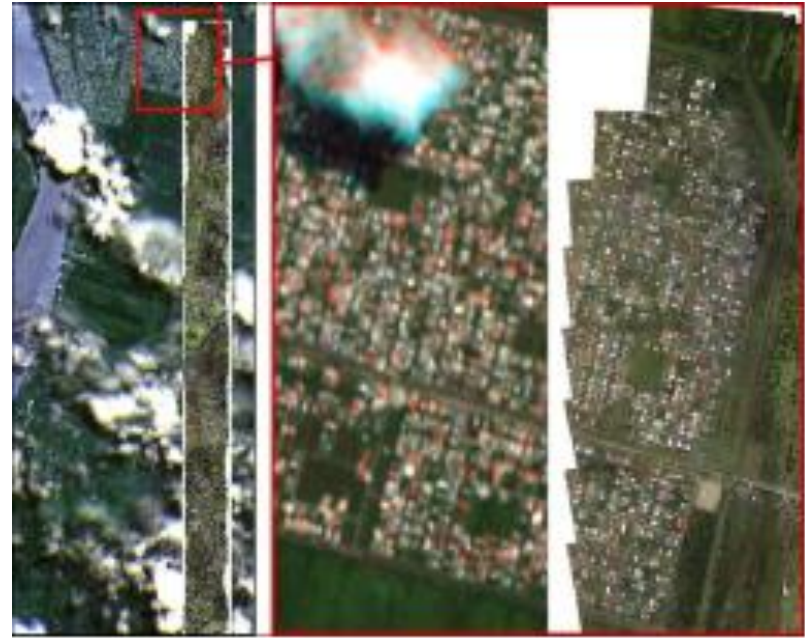

Figure 2: Comparative resolution of RapidEye and aerial imagery

\section{Image Processing}

The image processing steps have been automated using an ENVI 4.7 custom batch processing tool created on the IAP toolbar. The user can select to perform the following processing:

- Create tiles from swaths

-Convert Domain Number to Reflectance

-Perform Dark Object Subtraction

-Produce an Enhanced Vegetation Index

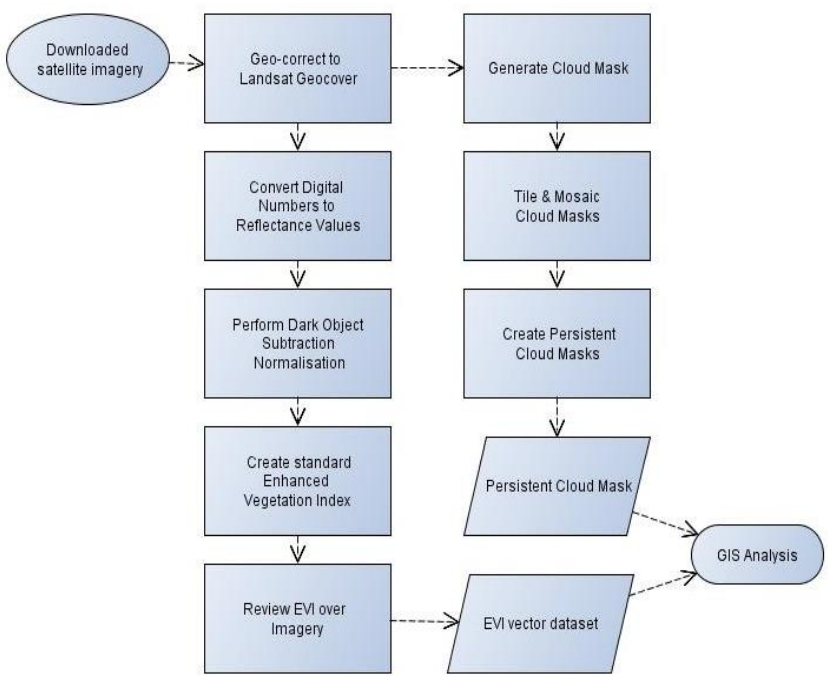

Figure 3: Image processing flow diagram (C) The Guyana Forestry Commission and Indufor 2013

\subsection{Image Geo-correction}

To ensure consistency across datasets all imagery is georeferenced to a base mosaic image which was generated from data provided in MrSid format by the Global Land Cover Facility (GLCF). The GLCF holds a global set of regional images which are divided into tiles and overlap each other seamlessly at their edges. This ensures consistency between images of a similar type, and also between different image types and resolutions. All satellite images are co-registered to the
2005 Landsat Geocover base map. Accurate co-registration is important to ensure that changes detected in future time periods are valid and not simply artifacts caused by inaccurate coregistration. Mismatches should be less than one Geocover pixel $(<14.25 \mathrm{~m})$.

\subsection{Image Normalisation}

Radiometric normalisation is a recommended image processing practise to ensure the radiometric values within images obtained over different time periods and by different sensors are calibrated to common reference values. There are many methods applied for the normalisation of images that perform either a relative correction to a single scene or an absolute correction to standard reflectance units.

For practical purposes based on the project timeline, the number of RapidEye images to process, the generally high level of clouds per image and the availability of atmospheric correction data, the dark subtraction radiometric normalisation method implemented in ENVI was chosen. Each scene is evaluated and the band minimum Digital Number (DN) values were automatically selected from each scene and subtracted from all pixels within the scene with the assumption the band minimum values are dark targets that are only influenced by atmospheric scattering.

The method of change detection adopted uses a combination of automated (calculation of vegetation indices) and manual interpretation and editing. The objective of the approach was to use a vegetation index to delineate areas of forest and nonforest. Identified areas of non-forest within the forest mask represent potential areas of forest change (i.e. deforestation or degradation). The delineated non-forest areas were input into a GIS and used as an ancillary layer in the Year 4 change analysis mapping.

The key to differentiating forest from non-forest is to link the reflectance properties of the vegetation to its structure. Several vegetation indices exist that enhance non-forest detection as described by Asner (1998).

For this work the Enhanced Vegetation Index (EVI) as described in Huete et al. (1997) was favoured over other vegetation indices as it includes the blue reflectance. The strength of the EVI is in its ratio concept which provides a correction for soil background signal and reduces atmospheric influences, including aerosol scattering. This is particularly relevant given the lack of any aerosols, water vapour, and ozone concentrations to correct atmospheric conditions.

The EVI is calculated with the following equation as presented and described in Huete et al 2002,

$$
\mathrm{EVI}=G \frac{\rho_{\mathrm{NIR}}-\rho_{\text {red }}}{\rho_{\mathrm{NIR}}+C_{1} \times \rho_{\text {red }}-C_{2} \times \rho_{\text {blue }}+L}
$$

where $G$ is the gain factor, $\rho$ are atmospherically corrected or partially atmosphere corrected (Rayleigh and ozone absorption) surface reflectances, $L$ is the canopy background adjustment that addresses nonlinear, differential NIR and red radiant transfer through a canopy, and $C 1, C 2$ are the coefficients of the aerosol resistance term, which uses the blue band to correct for aerosol influences in the red band. The coefficients adopted in the EVI algorithm are, $L=1, C 1=6, C 2=7.5$ and $G=2.5$. 
The EVI values range from 0 to 1 with low values indicating non-vegetative surfaces and those closer to 1 representing closed canopy forest. The same approach was successfully applied to separate forest and non-forest components for the 1990-2010 period $^{1}$.

The method has also been widely discussed in the scientific literature. Deng et.al. (2007) found that EVI was effective in vegetation monitoring, change detection, and in assessing seasonal variations of evergreen forests. The automated change detection process produces a vector layer delineating the potential areas of non-forest. The vector layer is subsequently input into the GIS for review, editing and attribution.

\subsection{Persistent Cloud Mask}

One potential issue is detection of change in areas of sporadic and persistent cloud. In areas of sporadic cloud (i.e. where at least one period is clear) the change was attributed to the relevant change period. If areas are under persistent cloud cover then it is not possible to evaluate the area for change.

The impact of cloud was assessed by generating cloud masks for each RapidEye and Landsat image to identify those areas of persistent cloud. Coincident pixels that are cloudy in all time periods are defined as persistent cloud coincident pixels that are nodata in all time periods are defined as persistent no data.

The masks were generated by a simple band threshold approach and edited to remove areas of non-forest. The cloud mask does not identify cloud shadow so it provides only a broad estimate of cloud coverage.

The analysis showed that for Year 4 less than $0.2 \%$ of the land area was persistently covered in cloud. The distribution of the cloud is quite scattered and located over the country most notably in the SE and NW of the country as shown on Figure 2.

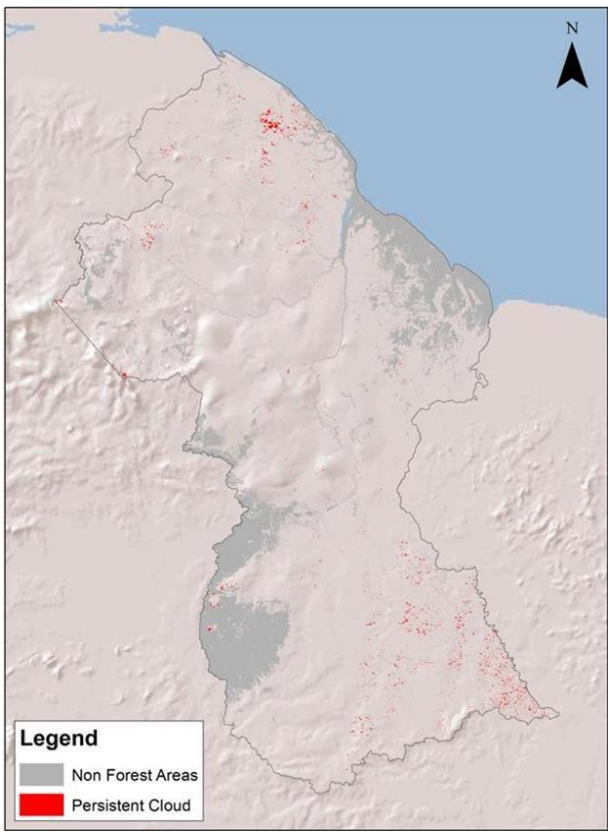

Figure 4: Persistent Cloud Cover (c) The Guyana Forestry Commission and Indufor 2013

\footnotetext{
${ }^{1}$ The independent accuracy assessment conducted in 2011 reported the accuracy of the forest and non-forest mapping to be $99 \%$.
}

\section{Spatial Mapping of Land Cover Change}

The GIS-based monitoring system is designed to map change events in the year of their occurrence and then monitor any changes that occur over that area each year. The process developed aims to enable areas of change ( $>1$ ha) to be tracked spatially through time, by driver (i.e. mining, infrastructure and forestry). The approach adopted seeks to provide a spatial record of temporal land use change across forested land (commensurate to an Approach 3). The mapping process involves a systematic review of each $24 \times 24 \mathrm{~km}$ tile, divided into $1 \mathrm{~km} \mathrm{x} 1 \mathrm{~km}$ tiles at a resolution of 1:8000.

The EVI vector outputs from the change detection process are edited as required to delineate new change events. Change is attributed with the acquisition date of the pre and post change image, driver of change event, and resultant land use class. A set of mapping rules has been established that dictate how each event is classified and recorded in the GIS.

The input process is standardised through the use of a customised GIS tool which provides a series of pre-set selections that are saved as feature classes. The mapping process is divided into mapping and quality control $(\mathrm{QC})$. The QC team operates independently to the mapping team and is responsible for reviewing each tile as it is completed.

Potentially there is some overlap between drivers as the exact cause of the forest change can be difficult to determine. This is particularly relevant when deciding on the driver of road construction when mining and forestry areas use the same access routes. Supplementary GIS layers are also included in the decision-making process to reduce this uncertainty. The decision based rules are outlined in the mapping guidance documentation. This documentation held at GFC provides a comprehensive overview of the mapping process and rules. The two types of change events mapped are deforestation and forest degradation.

\subsection{Deforestation}

Formally, the definition of deforestation is summarised as the long-term or permanent conversion of land from forest use to other non-forest uses (GOFC-GOLD, 2010). An important consideration is that a forested area is only deemed deforested once the cover falls and remains below the elected crown cover threshold (30\% for Guyana). In Guyana's context forest areas under sustainable forest management (SFM) that adhere to the forest code of practice would not be considered deforested as they have the ability to regain the elected crown cover threshold.

The five historic anthropogenic change drivers that lead to deforestation include:

1. Forestry (clearance activities such as roads and log landings)

2. Mining (ground excavation associated with small, medium and large scale mining)

3. Infrastructure such as roads (included are forestry and mining roads)

4. Agricultural conversion

5. Fire (all considered anthropogenic and depending on intensity and frequency can lead to deforestation).

In Year 4, a new driver 'settlements' has been added to the driver matrix. It allows the team to describe human settlement driven change such as new housing developments. 


\subsection{Degradation}

There is still some debate internationally over the definition of forest degradation. A commonly adopted definition outlined in IPCC (2003) report is:

"A direct human-induced long-term loss (persisting for $X$ years or more) of at least Y\% of forest carbon stocks [and forest values] since time $T$ and not qualifying as deforestation or an elected activity under Article 3.4 of the Kyoto Protocol ".

The main sources of degradation are identified as:

$\square$ Harvesting of timber (reported since 2011 using the Gain Loss Method)

$\checkmark$ Shifting cultivation (prototype method developed in 2012)

$\square$ Fire

$\square$ Associated with mining sites and road infrastructure

In Guyana forest degradation around deforestation sites is unique, with the main contributors being the opening of roads linked to new infrastructure, and degradation mainly associated with mining activity - which is dynamic.

The method development was supported by field inspections that measured the stock changes caused by degradation. The field assessment involved the establishment of field transects 20 $\mathrm{m}$ in width from the edge of deforestation events. The field measurements suggest that infrastructure-related degradation is restricted to the immediate area around the deforestation site.

Interpretation of the images showed that the forest cover returns to an intact state inside $40 \mathrm{~m}$ from the deforested event. Beyond this point it is possible to identify forest disturbances provided the disturbances are large enough $\left(>100 \mathrm{~m}^{2}\right)$ and the vegetation is disturbed to the point where the soil is exposed.

Further image coverages obtained in Years 3 and 4 indicate that degraded forest areas are either in transition to a state of deforestation or are only temporary in nature. It is also important to consider the possibility that historical mining sites may be re-entered or areas of small-scale prospecting extended. To ensure these activities are captured in the MRVS, the mapping team revisits all areas identified in preceding assessments (post 2011) using high-resolution imagery and update areas if changes have occurred.

4.2.1 Monitoring and Updating Degradation Event: When updating an historical forest degradation event there are 3 possible updates that can be applied to any one polygon, these are:-

The historical polygon still shows signs of degradation over the area in the recent imagery. In this case it appears there is still activity, and the area shows minimal canopy evidence of reforestation or abandonment of the area.

-Driver - Existing historical driver

-EndLUC - Degraded Forest by type

The polygon no longer shows any visible sign of degradation. The forest canopy has closed and it appears as though the area is now free of anthropogenic activity.

- Driver - Reforestation

-EndLUC - Degraded Forest by type

The polygon has been deforested.

-Driver - As appropriate according to the mapping guide

-EndLUC - As appropriate according to the mapping guide

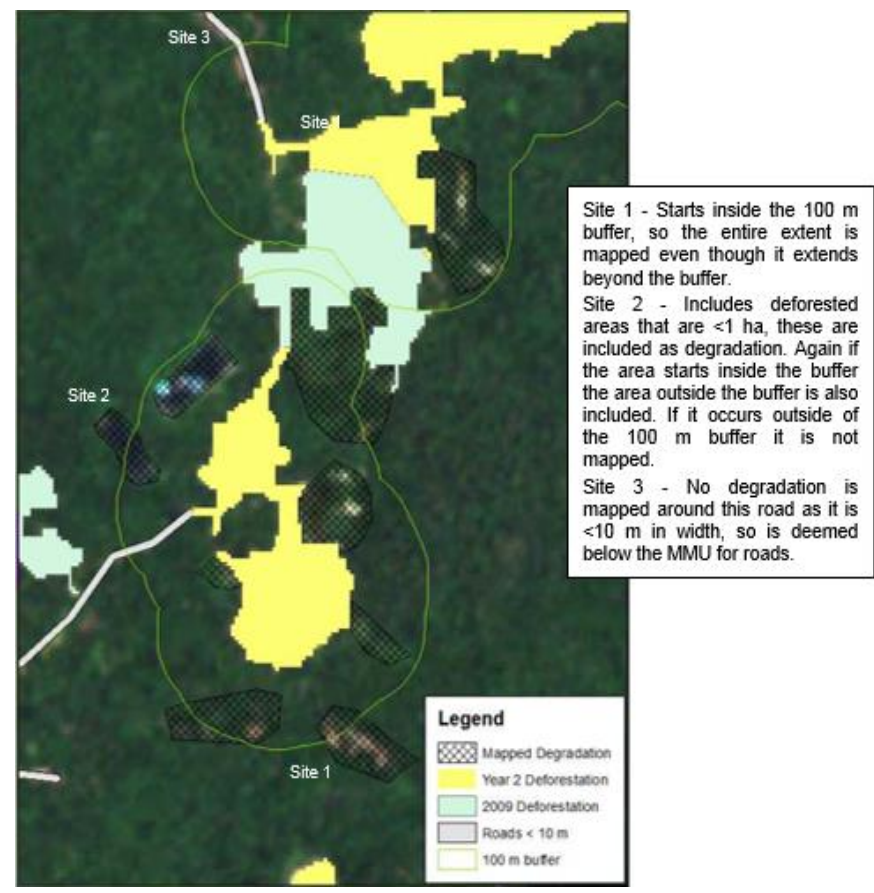

Figure 5: Change mapping (C) The Guyana Forestry Commission and Indufor 2013

4.2.2. Monitoring Shifting Cultivation: In Year 4, for the first time new shifting agriculture areas are reported under forest degradation. An evaluation of methods for detecting and mapping of areas under shifting cultivation has been undertaken. There are currently no best practice methodologies for doing this, especially on a national scale.

An appropriate detection and mapping methodology has been developed and operationalised in the year 4 analysis. The method adopted allows the calculation of the area which tracks newly cleared areas $>0.25$ ha. This is much smaller than the 1 ha minimum mapping unit (MMU) applied to deforestation. Shifting agriculture has been sub-categorised into:

- Pioneer; which consists of newly cut consists of newly cut areas which were seen as high forest in the previous year. All available evidence suggests these areas have not historically been degraded or anthropogenically affected. They tend to occur around the fringes of historical rotational shifting cultivation areas. A $100 \%$ carbon loss is assumed here as the pre change landcover was high forest.

- Rotational shifting cultivation consists of historically degraded and impacted areas. All available evidence suggests these areas are in various states of succession from newly burnt areas to late successional secondary forest areas. They tend to occur around the areas of long term human habitation. Field work is required to determine a carbon value/emission factor for these systems, as they are technically 'forest remaining forest'.

Further work is required to confirm the emission and removal factors for areas under shifting cultivation. Once calculated these can be linked to the spatial representation. This will enable a calculation of the carbon stock change to be included in the MRV. 


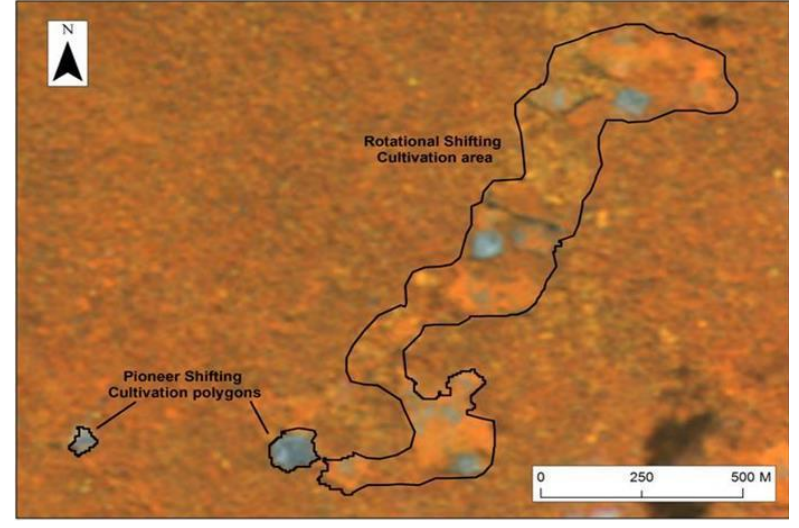

Figure 6: Shifting cultivation example (C) The Guyana Forestry Commission and Indufor 2013

\section{Forest Area Analysis}

Based on the initial 1990 forest area, the forest cover change for the 1990-2009 period is estimated at $0.41 \%$ (i.e. $<1 \%$ ). As with Year 1, the FAO (1995) equation as cited in Puyravaud (2003) has been used to calculate the annual rate of change. Puyravaud (2003) suggests an alternative to this equation, but at low rates of deforestation the two are essentially the same.

$$
q=\left(\frac{A_{2}}{A_{1}}\right)^{1 /\left(t_{2}-t_{1}\right)}-1
$$

Whereby the annual rate of change (\%/yr or ha/yr) is calculated by determining the forest cover $\mathrm{A} 1$ and $\mathrm{A} 2$ at time periods $\mathrm{t} 1$ and $\mathrm{t} 2$.

If the 1990-2009 period is annualised this represents an average rate of change of about $3800 \mathrm{ha} / \mathrm{yr}-1$ which is equivalent to a deforestation rate of $-0.02 \% / \mathrm{yr}$.

From this point the deforestation increased for the Year 1 period to $0.06 \%$ and has remained at a similar level for Year 2 $(0.054 \%)$. The rate is in fact lower $(0.043 \%)$ if the change is expressed as an annual rate rather than presented for the entire Year 2 period.

In Year 3 the deforestation rate increased relative to previous years to $0.079 \%$, but in Year 4 a decrease has occurred to $0.068 \%$

Overall, Guyana's Year 4 deforestation rate is low when compared to the rest of South America, which according to the FAO 2010 forest resource assessment (FRA) is tracking at an annual deforestation rate of $-0.41 \% / \mathrm{yr} 12$.

The trend shows that deforestation rates have increased since 1990 and peaked in 2012. From 2009-10 onwards the deforestation rate has fluctuated between $0.054 \%$ and $0.079 \%$. A decline in deforestation compared to 2012 is observed in 2013.

Significant progress was made in Years 3 and 4, in mapping forest degradation. The main cause of degradation in Year 4 continues to be mining which accounts for $68 \%$ of all degradation mapped. This is expected as mining also accounts for the largest area of deforestation. The established trend is that forest degradation impacts are largely detected around mining areas. The remaining contributors to degradation are from newly established shifting agriculture areas (18\%), fire (9\%), roading construction and settlements $(3 \%)$, and forestry related activities such as degradation during road formation $(\sim 1 \%)$.

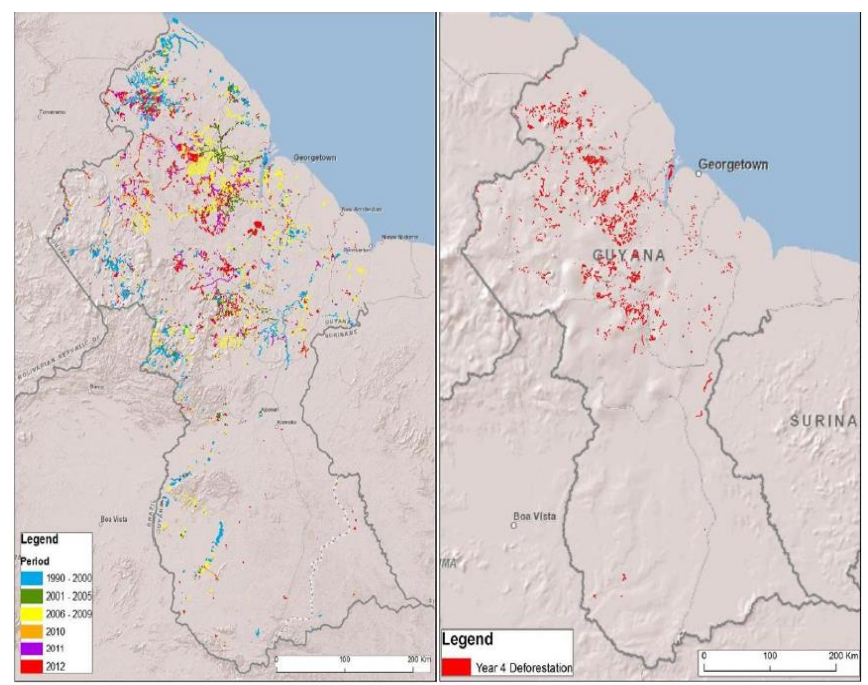

Figure 7: Historical and year 4 forest change (c) The Guyana Forestry Commission and Indufor 2013

\begin{tabular}{|c|c|c|c|c|c|c|c|c|c|c|}
\hline \multirow{3}{*}{ Driver } & \multicolumn{3}{|c|}{ Historical Period } & \multirow{2}{*}{$\begin{array}{l}\text { Year } 1 \\
2009-10 \\
\end{array}$} & \multicolumn{2}{|c|}{$\begin{array}{c}\text { Year } 2 \\
2010-11 \text { (15 months) } \\
\end{array}$} & \multicolumn{2}{|c|}{$\begin{array}{l}\text { Year 3 } \\
2012 \\
\end{array}$} & \multicolumn{2}{|c|}{$\begin{array}{l}\text { Year } 4 \\
2013 \\
\end{array}$} \\
\hline & $\begin{array}{c}1990 \text { to } \\
2000\end{array}$ & 2001 to 2005 & $\begin{array}{c}2006 \text { to } \\
2009\end{array}$ & & Deforestation & Degradation & Deforestation & Degradation & Deforestation & Degradation \\
\hline & \multicolumn{10}{|c|}{ Area (ha) } \\
\hline $\begin{array}{l}\text { Forestry (includes } \\
\text { foresty } \\
\text { infrastructure) }\end{array}$ & 6094 & 8420 & 4784 & 294 & 233 & 147 & 240 & 113 & 330 & 85 \\
\hline $\begin{array}{l}\text { Agriculture } \\
\text { (permanent) }\end{array}$ & 2030 & 2852 & 1797 & 513 & 52 & $\mathrm{NA}$ & 440 & 0 & 424 & NA \\
\hline $\begin{array}{l}\text { Nining (includes } \\
\text { mining } \\
\text { infrastucture) }\end{array}$ & 10843 & 21438 & 12624 & 9384 & 9175 & 5287 & 13516 & 1629 & $" 11251$ & 2955 \\
\hline Infrastructure & 590 & 1304 & 195 & 64 & 148 & 5 & 127 & 13 & 278 & 112 \\
\hline Fire (deforestation) & 1708 & 235 & & 32 & 58 & 28 & 184 & 208 & 96 & 395 \\
\hline \multicolumn{9}{|l|}{ Settlements } & 23 & 20 \\
\hline \multicolumn{9}{|c|}{ Year 4 Shititing Agriculture } & & 765 \\
\hline Year 2 forest degradat & tion convertec & d to deforesestatio & & & & & 148 & & 67 & NA \\
\hline \multicolumn{9}{|c|}{ Year 3 forest degradation converted to deforestation } & 200 & NA \\
\hline $\begin{array}{l}\text { Amalla Falls } \\
\text { development } \\
\text { (Infrastructure } \\
\text { Roads) }\end{array}$ & & & & & 225 & & & & 64 & 20 \\
\hline Area Change & 21267 & 34249 & 19400 & 10287 & 9891 & 5467 & 14655 & 1963 & 12733 & 4352 \\
\hline $\begin{array}{l}\text { Area Change for } \\
\text { Year } 4 \text { without } \\
\text { Shiting Agiculture }\end{array}$ & & & & & & & & & & 3587 \\
\hline $\begin{array}{l}\text { Total Forest Area of } \\
\text { Guyana }\end{array}$ & 18473394 & 18452127 & 18417878 & 18398478 & 18388190 & & 18502531 & & 18487876 & \\
\hline $\begin{array}{l}\text { Total Forest Area of } \\
\text { Guvana Remaining }\end{array}$ & 18452127 & 18417878 & 18398478 & 18388190 & 18378299 & & 18487876 & & 18475143 & \\
\hline $\begin{array}{l}\text { Period } \\
\text { Deforestation (\%) }\end{array}$ & $0.01 \%$ & $0.04 \%$ & $0.02 \%$ & $0.056 \%$ & $0.054 \%$ & & $0.079 \%$ & & $0.068 \%$ & \\
\hline
\end{tabular}

**Forestry infrastructure accounts for the full total of deforestation from forestry activities.

**Mining Infrastructure accounts for 918 ha in 2013 out of the total deforestation driven by mining of 11518 ha, when Year 2 \& 3 transitional areas are taken into account.

***Amalia Falls Development has been split from other infrastructure driven change for reporting purposes.

Table 1: Forest change area by period and driver from 1990 to 2013 


\section{Present and Future Development Areas}

Guyana has established a robust MRVS that is able to spatially account for the area of deforestation and degradation with confidence. It is envisaged that the reference measure as well as the interim performance indicators will only apply while aspects of the MRVS are being developed and will be phased out and replaced by a full forest carbon accounting system as methodologies are proven. The future focus is to enhance the MRVS to ensure it keeps abreast of international best practice guidance, new datasets, processes and routines. Specifically these developments include:

Development of a second reporting framework aligned to the IPCC Land Use, Land-Use Change and Forestry (LULUCF) template for annual assessments. This is based on the IPCC 2003 GPG tabular format. The LULUCF area change has been reported formally for the first time in November 2014

-Further sub-division of the non-forest area into the relevant IPCC classes. In preceeding reports this area has been presented as 'non-forest'.

-Development of methodology and guidelines for mapping and monitoring shifting cultivation.

-Development of relevant emission factors for degradation due to forest harvesting activities. Further work is on-going to determine appropriate emission factors for other forms of forest degradation.

-Integration of carbon measurements with spatial datasets to create activity-specific emission factors for degradation and shifting cultivation. This work is in on-going collaboration with Winrock International.

-Alignment of the Community MRV (CMRV) to facilitate integration with the national MRVS.

\section{Acknowledgements}

In addition to GFC, a number of agencies and individuals have assisted in providing inputs into the MRVS programme. GFC would like to recognise Indufor Asia Pacific for the technical contribution and guidance. We would like to acknowledge the support of the Ministry of Natural Resources and the Environment and the Office of Climate Change for their strategic guidance. The continued support and oversight of the members of the Multi-Stakeholder Steering Committee of the LCDS are also especially acknowledged. The GFC team would also like to acknowledge the following colleagues for their support; Winrock International for work on the forest carbon monitoring system, Conservation Iinternational for their role in supporting the implementation of this, as well as other aspects of the Guyana MRVS, the project team of Global Canopy Programme, North Rupununi District Development Board and the North Rupununi communities, Kanashen Village, World Wildlife Fund, Iwokrama and other partners working on the CMRV Project, Guiana Shield Facility and UNDP for supporting work under the MRVS and other partners.

\section{References}

Asner G.P., 1998, Biophysical and Biochemical Sources of Variability in Canopy Reflectance, Remote Sensing of Environment, 64:234-253.
Brown, S. and Braatz, B. 2008. Methods for estimating CO2 emissions from deforestation and forest degradation. Chapter 5 in GOFC-GOLD. Reducing greenhouse gas emissions from deforestation and degradation in developing countries: a sourcebook of methods and procedures for monitoring, measuring and reporting.GOFC-GOLD Report version COP 13-2. GOFC-GOLD Project Office, Natural Resources Canada, Alberta, Canada.

COP 7 29/10 - 9/11 2001 MARRAKESH, MOROCCO MARRAKESH ACCORDS REPORT (www.unfccc.int/cop7) FAO Forest Resource Assessment, 2010 http://foris.fao.org/static/data/fra2010/FRA2010_Report_1oct20 10.pdf

Deng, F., Su, G., \& Liu, C. (2007).Seasonal variation of MODIS vegetation indices and their statistical relationship with climate over the subtropic evergreen forest in Zhejiang, China.IEEE Geoscience and Remote Sensing Letters, 4(2), 236-240.

GOFC-GOLD Sourcebook 2010. A sourcebook of methods and procedures for monitoring and reporting anthropogenic greenhouse gas emissions and removals caused by deforestation, gains and losses of carbon stocks in forests remaining forests, and forestation GOFC-GOLD. Report version COP16-1, (GOFC-GOLD Project Office, Natural Resource Canada, Alberta, Canada).

Hansen, M.C., Stehman, S.V., Potapov, P.V., Loveland, T.R., Townshed, J.R.G., DeFries, R.S., Pittman, K.W., Arunarwati, B., Stolle, F., Steininger, M.K., Carroll, M. and DiMiceli, C. Copyright $(\odot)$ The Guyana Forestry Commission and Indufor 64 2008. Humid tropical forest clearing from 2000 to 2005 quantified by using multitemporal and multi-resolution remotely sensed data. PNAS 105(27):9439-9444.

Huete, A.R., H. Liu, K. Batchily, and W. van Leeuwen, 1997. A Comparison of Vegetation Indices Over a Global Set of TM Images for EOS-MODIS. Remote Sensing of Environment 59(3):440-451.

IPCC Report on Definitions and Methodological Options to Inventory Emissions from 15 Direct Human-induced Degradation of Forests and Devegetation of Other Vegetation Types, 2003 (http://www.ipcc.ch/publications_and_data/publications_and_da ta_reports.htm\#2)

Watt, P.J., Haywood, A.H., 2007. Mapping Forest Clearfelling using MODIS Satellite Data. Contract Report 38A08772. New Zealand Ministry for the Environment. 